\title{
Notice of Editorial Transition
}

This issue of The American Review of Politics (Volume 34, Spring 2013Winter 2014) represents the final edition of the journal that will be published from its current home at the University of Arkansas. Following the completion of a lengthy search, The American Review of Politics is pleased to announce a new editorial team and host institution. The incoming editors are Ronald Keith Gaddie of the University of Oklahoma, Charles Bullock of the University of Georgia, Scott Buchanan of the Citadel, and Justin Wert of the University of Oklahoma. The University of Oklahoma will serve as the new host institution for the journal.

The new team will begin accepting manuscripts for review for Volume 35 in August 2014. Please contact Professor Gaddie at rkgaddie@ou.edu for information about new submissions. 